\title{
Sense and sensibilities: Schoolboys talk about sex in the private conversational space
}

Kaymarlin Govender, Leigh Adams Tucker and Sarah Coldwell

\begin{abstract}
This article focuses on the narratives of 18 adolescent boys as they engaged with issues of sex, sexuality and peer relations in their daily lives. The ethnographic research was conducted in two public secondary schools in a working-class community within KwaZulu-Natal, South Africa. Participants were boys aged between 16 and 19 years, who self-identified as either Black African or Indian. Theories of positioning are employed in this paper to delve into the complexity and intricacies of boys enacting their masculinities and sexual identities within a one-to-one interview space with one of the researchers. Identity performance in this private space is read in relation to public positions (in the company of peers), exposing the malleable nature of positioning and its subjective use in different spaces. Findings suggest that boys' struggle with the concept and social practice of 'masculinity', and that while they may not want to be seen as aspiring to certain ideals regarding male sexuality, these values remain a standard against which to evaluate self and other. In the individual interviews, authenticity as a heterosexual man is negotiated through various rhetorical strategies, namely a tendency to self-position as mature and sensible. It is argued that positionality is a useful conceptual tool for highlighting diversities in the performance of masculinities, and that intervention strategies need to pay attention to how spaces are constructed and nurtured for boys to engage with the ideological dilemmas in their identity development.
\end{abstract}

Adolescence is typically regarded as a tumultuous developmental period, in which biological maturation intersects with increasing personal responsibility and exposure to diverse opportunities for social interaction. During this time, young men are often depicted as experiencing heightened sexual drives relative to their female peers with social pressures to demonstrate sexual prowess. Much of the research in sub-Saharan Africa on heterosexual masculinity points to the prevailing narratives of 'risky' young men adhering to social norms on sexual permissiveness and engaging in multiple sexual activities as they transition from youth to adulthood (Anderson, 2010; Brown, Sorrell, \& Raffaelli, 2005; Langa, 2010; Shefer, Kruger, \& Schepers, 2015; Sommer, Likindikoki, \& Kaaya, 2015; Wood \& Jewkes, 2001).

Hegemonic masculinity has been applied to the field of sexual health research as a way to understand men's sexual practices and health outcomes, and has been expanded in the 
South African context in acknowledgement of the presence of multiple dominant masculinities (Jewkes \& Morrell, 2010; Lindegger \& Quale, 2009; Morrell, Jewkes, \& Lindegger, 2012). Attributes of hegemonic masculinities have included physical strength, courage, independence and self sufficiency, toughness, sex with multiple partners, fearlessness and men's exercise of control over women and other men.

While these features of masculinity have been exalted in previous times, changes in the order of gender relations which have accompanied workplace and industrial shifts, have contributed to a contemporary 'crisis' of masculinity, which has seen the rise of the feminist movement and for many, the collapse of the legitimacy of patriarchal power (Connell, 2005). Tensions arising from changing attitudes to sexual inequality and mens' rights accompanying the rise of the women's movement has also influenced the shift towards gender sensitive discourses in a post-democracy South Africa. It is therefore not surprisingly that traditional attributes of masculinity as violent, sexually dominant, emotionally detached and fatalistic (Bhana \& Pattman, 2011; Lindegger \& Quale, 2009; Shand, Thomson-de Boor, van den Berg, Peacock, \& Pascoe, 2014), has been recently problematised in the South African public space (Brown et al., 2005; Ratele, 2008).

Since adolescence is a time when transitions of masculine identities by young men becomes especially salient, tensions are likely to be activated between the lived experience and what is deemed as acceptable forms of self-identity and self-presentation for young men in society. In this regard, there is a limited body of work on childhood and adolescent masculinities that documents the challenges that adolescent boys face under pressure to conform to hegemonic masculine norms in contexts of sexuality, HIV, poverty and disempowerment (Govender, 2011; Gibbs, Vaughan, \& Aggelton, 2015; Reardon \& Govender, 2011; Shefer et al., 2015).

\section{Positioning Theory and Performativity}

Positioning theory provides an in-depth account of the relationship between discourse and psychological phenomena (Yamakawa, Forman, \& Ansell, 2005). Subject positions are assumed within discourses, put more simply, we adopt a role of being, a sense of 'self' in relation to the 'other' (Davies \& Harré, 1990; Harré \& van Langenhove, 1999). However, this sense of 'self' is seen as being in a constant state of transition. For this reason, many theorists now see subjectivities (which involve our reflections on ourselves and our emotions) as accomplished in particular situations with specific people (Butler 1993; Davies \& Harré, 1990; Edley \& Wetherell, 1997; Wetherell \& Edley, 1999, 2014). This sometimes means that people may find themselves in 'troubled subject positions' or 'ideological dilemmas' (Billig, 1991) if they are faced with contradictions that they have produced. These subject positions are disputed or accepted in language, as people have to explain, defend, or abandon them in the face of others' resistance.

Performance and performativity are integral to an understanding of gender, and is a useful vantage point to view masculinity as a situated performance. This view is consistent with the work of seminal identity theorists like Butler (1993), who stress the complex and 
active ways in which gender is produced and performed through repetitive acts, giving it the appearance of something 'solid', which individuals possess. Interviews are seen as everchanging discursive practices, and sites for 'acting' or 'performing' or 'resisting' particular story lines and participant roles (Yamakawa et al., 2005). Therefore, boys' accounts in different kinds of interviews or at different points in an interview might reveal different facets of their masculinities. Phoenix, Frosh, and Pattman (2003), in their early UK study, observed that boys were likely to be more sensitive and reflective in their personal accounts when talking in private with study researchers, as compared to the peer group. Recent literature has worked to acknowledge and understand these shifting disclosures and narratives of sexuality within male peer group culture (Chu, 2005; Dalley-Trim, 2007).

Previous research on schooling and masculinities in South Africa has focused on identity work in relation to issues of racism, school violence and sexuality (Bhana \& Pattman, 2011; Gibbs et al., 2015; Govender, 2011, Tucker \& Govender, 2016), however work is limited on the situated contexts of interactions and contingent nature of identities. Given the limited research about the processes and politics of such work in masculinities, the main aim of this paper is to report on research about schoolboy perspectives of sex and relationships, to explore the complex positions that these young men assume across contexts in relation to normative pressures toward heterosexuality.

\section{Methods}

\section{Sampling and Ethical Considerations}

Data for this paper is drawn from a larger ethnographic study conducted in South Africa in 2011, focusing on adolescent schoolboys' accounts of sexuality, sexual practice, and peer relations. Formal permission to conduct the research was granted by the University of KwaZulu-Natal Ethics Committee, as well as the provincial Department of Basic Education. Participants were drawn from two public co-educational secondary schools in Phoenix, a working class community located on the outskirts of the Durban Metro Region of KwaZuluNatal in South Africa. Phoenix, which was demarcated as a residential site for Indian families during Apartheid, remains a comparatively under-resourced area, where workingclass Indian and Black families reside in either formal or informal housing arrangements.

The study focused on adolescent boys within the more senior years of schooling, specifically Grades 10 and 11, where there is not only greater opportunity to interact with female peers, but also institutional hierarchies and status relative to peers in junior grades. Participants self-identified as either Black African or Indian, and were typically aged between 16 and 19 years. Participants were recruited on an informal basis through friendship groups during play breaks in the schoolyard using a snowball-sampling method (Babbie \& Mouton, 2003).

The potentially sensitive nature of conversations regarding sex and sexuality made it necessary to safeguard the privacy of participants. Confidentiality of interviews was assured and participants were informed that involvement in the study was voluntary and that they could terminate the conversation with the researcher at any point during the 
interview session. Interviews were audio recorded with express written permission of participants and guardians. Furthermore, pseudonyms were used in the reporting of findings to maintain confidentiality and protect the identity of participants. Post the interview; participants who requested counselling related to issues of sexuality, sexual practice, bullying or harassment were referred to the school counsellor on a confidential basis. The head teacher of the grade was also informed on the issue without disclosing individual details of participants.

\section{Data Production and Analysis}

In the first phase of data collection, the narratives of 58 boys were elicited in semi-structured peer group discussions. These discussions were facilitated with brief descriptive vignettes related to relationship expectations, real or anticipated sexual practices, and desirable or undesirable features within partnerships. Following the group discussions, boys were invited to attend individual interviews. Eighteen boys voluteered to participate in the one-to-one interview context with the lead researcher, to explore their perceptions of the group discussion and to elicit commentary in relation to the themes identified. Interviews were of approximately 45 min duration and occurred during play breaks or free lesson periods in order not to conflict with teaching time.

As mentioned previously, interviews are not seen as instruments for eliciting 'truth' about boy experiences, but as particular contexts where boys perform, display, and experience aspects of boyhood. As such, the nature of these performances in the private space need to be read against the previous accounts of the public or peer space (Govender, 2011), thereby exposing the malleable nature of positioning and its subjective use in different contexts.

Analysis was undertaken using Edley's (2001) method of discourse analysis. The initial step entailed the primary author reading and re-reading the interview transcripts, while making impressionistic notes. This content was engaged with by the lead researcher in a supervisory peer context to generate a range of interpretive repertoires, which are seen as a "relatively coherent way ... of talking about objects and events in the world" (Edley, 2001, p. 198). These emergent interpretations were viewed in relation to existing literature within the field of young masculinities, in order to ground the analysis within a larger empirical and theoretical framework. Beyond generating possible systems of meaning, multiple other readings of the transcripts took place to explore the rhetorical strategies that participants employed to justify particular subject positions (Potter \& Wetherell, 1987), and negotiate potential 'ideological dilemmas' (Billig, 1991). This iterative process between theory and findings supports a line of argument for how this paper contributes to understandings of boyhood in this context.

\section{Engaging with the Boys}

In engaging with the boys, the first author adopted an informal conversational style in aiming to create a non-judgmental and affirming atmosphere. However, these interactions were already inscribed with a range of discursively constructed positions-such as the adult- 
child, teacher-student, and researcher-interviewee. Therefore, as an educated adult male, attempts to offset power relations and views of expertise may not have been completely successful. For instance, in conversations regarding sexual practice and heterosexual relationships, the boys frequently asked questions such as: "What do you think?" "Is this the right way?", or "What should I do?"

Boys at the study sites displayed varying levels of enthusiasm in response to requests to be individually interviewed as a follow-up to the group interviews. While some boys were eager to be interviewed, others declined. These were not outright refusals, rather hesitations and avoidances or brush-offs, as per the response of one boy: "Not today. Maybe later in the week". Postponing or delaying participation was an effective rhetorical device to 'save face,' without coming across as dismissive.

Others indicated their preference for the group interview, as noted by one boy's reply, "Err, I don't know. Why don't you talk to us in a group like before?" or confidently asserted that they had nothing additional of value to say in a one-to-one interview. This latter position of withdrawing and refusing to participate corresponds to the cultural narrative of the emotionally inarticulate and emotionally unavailable male (Frosh, Phoenix, \& Pattman, 2002; Pollack 1998). However, curiosity about the individual interview was demonstrated in other ways. For instance, an interview being conducted in a vacant classroom was interrupted by boys either trying to peer into the room to see what was going on or knocking at the windows and running off. This can be read as a mocking gesture by boys to challenge the relation of power that was set up in the 'confessional' encounter behind closed doors.

In the peer group discussions, as noted in a previous paper (Govender, 2011), most participating boys were loud, gregarious, and enthusiastically showed off their sexual exploits, while undermining and objectifying their female peers, and teasing or joking about boys who did not seem to engage in this heterosexual ritual. However, in the individual interview, boys openly admitted to "talking shit" in the group, and were generally 'critical' of peers who lacked discipline and responsibility in sexual relationships. That being said, some boys participating in the individual interview, may have still dramatised this experience and undermined the interviewer's authority in order to retain masculine bravado among peers, such as the one young man who claimed post the interview that he had "handled" the interviewer's questions.

\section{Findings: Structuring Repertoires of a'Sensible Man'}

The following presentation of results illustrates the complex nature of reflexive positioning and its adaptability to meet circumstantial expectations, as boys (re)position from the focus group interviews to the one-on-one interview. Boys negotiate their authenticity as heterosexual men, through discursive subject positioning and rhetorical strategies (Edley \& Wetherell, 1997). The accounts of Michael, Enver, Neil, Rajen, and Robbie are highlighted to reveal how the boys rehearse self-positionings as 'Sensible' and 'Restrained' in opposition to the 'Irresponsible Other'. Analysis explores the repertoires of maturity that boys use to 
construct and affirm this position, as well as the potential incongruencies in this performance, in 'splitting' and reframing sexual desire.

The first excerpt presented below is produced from an individual interview with a Grade 11 Black student, Michael, where the first author probed his views regarding the group discussion. Michael derides his peers for their sexual exaggerations and questions the authenticity of their behaviour via remarks that they "like to talk about [sex] all the time" and that "most of them think that they are experienced but they are not".

Interviewer When you think of boys, do you think that they are more sexually active than other boys?

Michael Most of them think that they are experienced but they are not.

Interviewer What makes them think that they are?

Michael Those who think that they are like to talk about it all the time; they like to talk about what happened last night. If they carry on like this others will think that they really did it. If they are serious they think that No! This is something serious. I must keep it to myself.

Michael's repetition of the words "serious" and "think" in lines 3, 5-7 above, reinforce his claim to a more thoughtful and responsible subject position. Interestingly, Michael does not discount the value of sexual performance however he works to construct his privacy around these acts as a more authentic marker of masculine success. By subverting the boastfulness of his peers, Michael is able to come across as the more mature party, thereby gaining more respectability.

This tendency towards adopting a rational and responsible subject position, re-emerged in other individual interviews in the study, in relation to the issue of condom use. Overall, condom use was not popular among boys within the group interview, as there was a shared disdain for how condoms minimise pleasure (Govender, 2011). However, in the individual interview, boys like Enver, a Grade 11 student, reflect on the personal consequences of not using a condom:

Interviewer If the girl does not want to use a condom?

Enver You know, I don't think that I can do it, I will not agree. I have to think about our situation. I will tell her that I am still a child, living at home and I do not have money to even look after myself, and if I get a disease...I think I will have to break up with her if she disagrees.

Interviewer So you'll break up?

Enver What if she gets pregnant? What will I do if she got AIDS or maybe I have it?

Interviewer Do other guys think about this as well?

Enver They (sighs), not really, they just want to do it (sex), ...no time to think, they just follow the others (other males). I say, hey, I need to be careful and think about myself. I can make up my own mind. 
In articulating his support for condom use and reconciling the potential differences from his peers, Enver suggests in lines 10-12, that he does not "follow the others" and "can make up (his) own mind". In other words, he is able to reframe his masculine position as someone who exhibits self-control. However, Enver also adopts a reflexive stance in revealing various fears and layers of vulnerability, and defining what is perceived to be developmentally appropriate for someone his age. Not only does Enver readily label himself as a child (in line 3) but he also stresses his financial limitations in caring for a newborn, the possible uncertainty within his romantic relationships, and the risks of contracting HIV. These personal admissions significantly contrast with the bravado and invulnerability shown by boys during the group interviews.

In the earlier group discussions, Neil, a Grade 10 Indian student, was silent when other boys boasted about the number of girls that they pursued. It was through this silence that Neil became complicit in propagating the patriarchal dividend (Connell, 1995); that is the unquestioned privilege of men in society. However, in the individual interview, beyond the gaze of his peers, Neil presented himself as someone who is not readily interested in romantic relationships, while also confronting and exposing the other males on their "fooling around”.

Neil The players only run after girls.

Interviewer What do you mean?

Neil There are also other things in life that's more important.

Interviewer Like what?

Neil I want to grow up and be something, fooling around (with girls) gets you in trouble. Girls can mess you up. I don't care what they call me, one day I'll be laughing at them. Girls are for later.

Like Enver, Neil also makes reference to developmental repertoires, where youth are viewed as not being prepared for heterosexual relationships (i.e. "girls are for later"). Neil legitimately rejects being part of the heterosexualised parody of his peers, whilst positioning the self as more sensible and independent in "want(ing) to grow up and be something". The choice to concentrate on academics was, in Neil's version of things, not because of any heterosexual inadequacy, but his need to do what was necessary to be academically successful at school, to hold him in good stead for adult life. It is Neil's comment that "one day (he'll) ...be laughing at them", that points to this ongoing tension in resisting one aspect of masculinity while taking up another.

A further variation on the strategy of boys distancing themselves from the male sex drive discourse is presented in an interview with Rajen, a Grade 10 student. In this interview, the issue of having many sexual partners is broached. In the earlier group interviews, Rajen did not protest against the double standard of sexuality that condones multiple sexual partners for men but not for women. In the individual interview, however, he asserts himself as a sexually responsible agent in rejecting the idea of being unfairly labelled as a 'player', in being seen to be "using girls": 
Interviewer And you don't like the player?

Rajen No! If you are committed to one person, you must be committed to one person only. Interviewer And if someone calls you a player?

Rajen I will be frustrated and...

Interviewer Why will you be frustrated?

Rajen That's not like me [10]

Interviewer How do you feel about being called a player?

Rajen Bad things. I feel bad because this is not me. It's like using the girls?

Interviewer And you don't like it? Why?

Rajen Because the girl will think that you are really committed to her. You are doing something wrong?

Rajen's dislike at being called a 'player', is shared in the initial work of Tillotson and Maharaj (2001), who note that the label held derogatory connotations among South African boys who are increasingly aware of a gender-conscientised society and threat of HIV infection. Later on in the interview, in response to the question: Do you have more than one girlfriend?-Rajen remarks that he has "other friends who are girls" (line 2). This is quick response to secure his heterosexual status, as boys should be seen to be socially comfortable with girls.

Interviewer Do you have more than one girlfriend?

Rajen I have other friends who are girls. We talk a lot about different things.

Interviewer Do they then call you a player?

Rajen It will be different because they will think I'm a player, but I'm not.

Interviewer And how does it make you feel?

Rajen Well you can't blame a person because you don't know what is happening to him or why he (sic) does that.

Interviewer Do you try and correct them?

Rajen Ja! [10]

Interviewer If someone calls you a player in a group of people, how do you feel?

Rajen Embarrassed. You feel bad, especially if you are in a group of girls and boys.

Interviewer Is there any other name that they will use for you?

Rajen Well the word, players is the common name.

While Rajen openly makes a distinction regarding being a player and having "friends who are girls", it was observed in the group interviews that some boys were teased by their male peers as "girly" or "sissy", because they frequently socialised with girls. This idea that gender difference and sexual desire are linked was shared in Frosh et al. (2002) seminal work, where adolescent boys who favoured the social company of girls were typically constructed as gay. In the excerpt below, Robbie, a Grade 10 student elaborates as to why he prefers the company of his female peers, stating that "girls are easy to talk to. They listen. They don't laugh at you. They are more mature than boys”. 
Robbie is able to support his decision by differentiating and elevating himself beyond his peers on the basis of maturity. This discourse echoes earlier participant claims regarding the masculine performance of sensibility and responsibility. This idealisation of female friendship, such as being "easy to talk to", listening, or being "more mature" than boys, cuts against the dominant discourse of the emotionally detached male (Frosh et al., 2002; Pollack, 1998).

Despite Robbie's rationalisation, the cost of being 'friendly' with girls suggests that Robbie may find it difficult to relate to girls in a heterosexual manner. In a manoeuvre not to be perceived as gay, Robbie engages in a discursive process of splitting, by desexualising the girls at his school:

Robbie No, not these girls! I like this girl at Rydal High (another school). I saw her at the mall.

Interviewer And the girls here?

Robbie Here we're just friends. I don't see them like that.

Interviewer Like what?

Robbie Like a girlfriend, we just friends.

The sexualisation of the unfamiliar woman is one attempt to hold off insinuations that being 'just friends' with the opposite sex can be seen as 'crossing over' the gender-divide, thereby ensuring that the 'discourse of difference' that is so central to heterosexuality is maintained (Shefer \& Foster, 2009).

\section{Discussion: The Rhetorics of (Re)producing 'New' Hegemonies}

The preceding analysis has highlighted some of the struggles among school going boys in the enactment of their masculinity. The influence of the interview space on boys' narratives revealed different levels and performances of masculinity in relation to the specific conversational demands of the topic. The series of (re)positionings that boys attempt across the group and individual interviews can be viewed as part of "the changing flow of positions we negotiate within social interaction" (Burr, 2003, p. 120). These positioning struggles, which are constituted in language, are a crucial site for identity negotiation and power relations.

Overall, it seems that the dialogical spaces availed within the private interview allowed alternate (vulnerable, sensitive, or dilemmic) ways of 'being male' to surface, where boys were enabled to express, in confidence, things that they were probably not willing to express in the presence of their peers. Many of these one-to-one interview excerpts reveal dissatisfaction with so called popular or hegemonic ways of 'being boy', resulting in boys feeling 'troubled' and driven to find alternate ways of being masculine.

Boys who actively resisted claims to 'getting a girl' defended their position in the individual interview by resorting to discourses of maturity and by constructing a difference of desire. A dominant theme across accounts was an attempt to be more mature or 
independently-minded than other boys. Connell (1995) argues that this is a "familiar theme in patriarchal ideology that men are rational/ sensible while women are emotional" thereby constituting a "major form of repression in contemporary society" (p. 164). One could also argue that the adoption of this reflexive self-position may be an indication of the popularity of psychological discourses of the self and the impact of feminist politics to negotiate more progressive masculine identities. For example, Rajen's earlier rejection of 'the player' may be an indication of internalised messaging regarding monogamy and faithfulness, a position that aligns with the emerging gender sensitive discourses in a postapartheid South Africa.

However, Wetherell and Edley (1999) assert that "perhaps what is most 'hegemonic' is to be non-hegemonic!-an independent male who knows his own mind and who can 'see through' social expectations" (p. 351). Therefore, rather than seeing these boys as being beyond gender power, boys may assert their superiority via individuality and autonomy, by contrasting themselves as different from the macho stereotypes of their peers.

The pressures for male culture to conform to 'doing heterosex' means that they have to delicately negotiate 'safe heterosexual' subjectivities that are seen to be acceptably masculine in an increasingly gender sensitive society. Not being careful in negotiating an appropriate subject position means that the heterosexual male is vulnerable to being labelled as a misogynist, or alternatively, labelled as being gay in contemporary public discourse. As such, heterosexuality could be called into question if boys fail to successfully demonstrate hegemonic forms of masculinity in other ways-usually through 'fighting' or sport (Bowley, 2013; Hamlall \& Morrell, 2012; McCormack \& Anderson, 2010; Parkes \& Conolly, 2013; Tucker \& Govender, 2016).

These dilemmas were manifested in the ways that boys strove to explain that although they did not fit one hegemonic ideal of masculinity, notably in terms of the male sex drive, they were nevertheless masculine.

\section{Limitations}

It is also important to note that while the repertoires presented by the authors may appear to be powerful, truthful and authentic accounts of boy voices, the author's representation is not necessary 'innocent', and interpretation will always remain a partial discourse, suspending the author as an absent-presence. Rather than treating the interviews as indexing pre-existing masculine identities, the conversational or discursive process between the interviewer and the boys, was itself, part of the cultural construction of masculine forms. The malleable nature of self-positioning is evident in the change in what boys said (and how they behaved) in individual interviews as compared to group interviews.

In being alert to this co-production of meaning, it is also acknowledged that being probed on issues of sexuality by an educated and older male researcher is likely to have encouraged the participants to speak about heterosexual relationships in a manner that was somewhat more gender sensitive, yet firmly heterosexual. For example, it is arguable that Neil and Enver, in the 
excerpts above, were only alerted to developmental issues because of the seniority of the interviewer. Therefore, in the context of this unique relational space, responses may be construed as collusion in perpetuating a model of male rationality and control.

\section{Implications for Practice}

The lessons derived from this study argue for the need to consider positionality as a useful conceptual tool for exploring diversities in masculinities when working with boys on issues of sexuality and sexual health. Researchers in the field of gender and health (Gibbs, Jewkes, Sikweyiya, \& Willan, 2014; Greene \& Barker, 2011; Jewkes \& Morrell, 2010; Peacock, Stemple, Sawires, \& Coates, 2009) argue that intervention strategies need to pay attention to nurturing spaces for boys to engage with the ideological dilemmas encountered as part of the identitymaking process.

Changing the situational dynamics of conversations (individual interviews and mixed gender peer conversations as opposed to the all-male peer group) may have the potential to disrupt prevailing narratives and present boys with chances to carve out different identities. At the same time, shoring up the struggles in masculine identities while seeking opportunities to constructively work with boys (as part of sexuality work) is not easily achieved in ephemeral-type interventions. Identity work is a complex enterprise and requires carefully thought out and long-term interventions.

The research also holds value in highlighting considerations around which individuals are best placed to work with adolescent boys in exploring potentially sensitive content regarding sex and sexuality. In this study, the lead researcher, as a male of colour, was physically and socially inscribed with values of 'sameness' in relation to the young male participants, thereby suggesting an 'authority' to connect and share in the matter of male sexuality. However, as previously discussed, the same researcher was distanced from his 'insider'

position by virtue of his seniority, academic advancement, and the social context of a research investigation, thereby creating constraints in what could or could not be said. As such, there is a need to carefully consider and prioritise the role of 'insider'/'outsider' positions and inter-subjectivity, the psychological relations between people, in shaping participation and engagement with individuals and groups in clinical and research settings. Reflection is important to evaluate the research process or efficacy of interventions, but it is equally important to activate these discussions within the intervention context or conversational space, to enable commentary for all parties.

\section{Conclusion}

Looking at the different ways in which people talk about boys, men and masculinity, one begins to understand sub-themes that were produced in the interviews as well as the kinds of limitations that exist for construction of 'self' and 'other' (Harré \& van Langenhove, 1999). This paper presents another linguistic turn in the conversation on masculinities, sex, and sexualities among adolescent boys. One does not see the boys' performances in individual interviews as being more authentic than those in groups, but rather to see each setting as drawing out different manifestations of masculine identity construction-different 
ways of 'doing boy'. It also demonstrates how hegemonic heterosexuality is contained and how the borders of heterosexuality are patrolled in different relational contexts and situated performances.

Contrary to the 'masculinity in crisis' discourse which serves to pathologise men's behaviour and limit recognition of the diversity of masculinities; our research suggests how adolescent boys do enact agency in responding to dominant discourses. These private conversations have shown that there is potential for boys to confront their perceived vulnerabilities and inconsistencies between word and practice within scripted forms of masculinity. However, the dominance of the responsible or 'sensible' position does not necessarily mean a reversion towards gender egalitarianism, or truly progressive gender relations. It is therefore important to develop more nuanced understandings of boys' experiences, rather than simply framing them in contrast to vulnerable femininities.

Acknowledgements This work was supported by the South African Institute of Race Relations (Grant No.: ustelp/udw/0289/2004); and the South African Medical Research Council [Grant No.: 0598/2006]. 


\section{References}

Anderson, B. (2010). Coloured' boys talk: Constructing heterosexual masculinities in a working class high school context. Journal of Psychology in Africa, 2O(4), 635-664.

Babbie, E., \& Mouton, J. (2003). The practice of social research. Cape Town: Oxford University Press Southern Africa.

Bhana, D., \& Pattman, R. (2011). Girls want money, boys want virgins: The materiality of love amongst South African township youth in the context of HIV and AIDS. Culture, Health \& Sexuality, 13(8), 961-972.

Billig, M. (1991). Ideology and opinions: Studies in rhetorical psychology. London: Sage.

Bowley, B. (2013). Soft boys, tough boys and the making of young sporty masculinities at a private boys' school. Agenda, 27(3), 87-93.

Brown, J., Sorrell, J., \& Raffaelli, M. (2005). An exploratory study of constructions of masculinity, sexuality and HIV/AIDS in Namibia, Southern Africa. Culture, Health \& Sexuality, 7(6), 585-598.

Burr, V. (2003). An introduction to social constructionism (2nd edn.). East Sussex: Routledge.

Butler, J. (1993). Bodies that matter: On the discursive limits of 'sex'. New York: Routledge.

Chu, J. Y. (2005). Adolescent boys' friendships and peer group culture. New Directions for Child and Adolescent Development, 2005(107), 7-22.

Connell, R. W. (1995). Masculinities. Cambridge: Polity Press.

Connell, R. W. (2005). Growing up masculine: Rethinking the significance of adolescence in the making of masculinities. Irish Journal of Sociology, 14(2), 11-28.

Dalley-Trim, L. (2007). The boys' present... Hegemonic masculinity: a performance of multiple acts. Gender and Education, 19(2), 199-217.

Davies, B., \& Harré, R. (1990). Positioning: The discursive production of selves. Journal for the Theory of Social Behaviour, 2o(1), 43-63.

Edley, N. (2001). Analysing masculinities: Interpretive repertoires, ideological dilemmas and subject positions. In M. Wetherell, S. Taylor \& S. Yates (Eds.), Discourse as data: A guide for analysis (pp. 189-228). London: The Open University.

Edley, N., \& Wetherell, M. (1997). Jockeying for position: The construction on masculine identities. Discourse and Society, 8(2), 203-217.

Frosh, S., Phoenix, A., \& Pattman, R. (2002). Young masculinities. New York: Palgrave.

Gibbs, A., Jewkes, R., Sikweyiya, Y., \& Willan, S. (2014). Reconstructing masculinity? A qualitative evaluation of the stepping stones and creating futures interventions in urban informal settlements in South Africa. Culture, Health \& Sexuality, 17(2), 208222.

Gibbs, A., Vaughan, C., \& Aggleton, P. (2015). Beyond "working with men and boys": (Re)defining, challenging and transforming masculinities in sexuality and health programmes and policy. Culture, Health \& Sexuality, 17(sup2), 85-95.

Govender, K. (2011). The cool, the bad, the ugly, and the powerful: Identity struggles in schoolboy peer culture. Culture, Health \& Sexuality, 13(8), 887-901.

Greene, M., \& Barker, G. (2011). Masculinity and its public health implications for sexual and reproductive health and HIV prevention. In R. Parker \& M. Sommer (Eds.), Routledge handbook in global public health (pp. 199-207). Abingdon: Routledge. 
Hamlall, V., \& Morrell, R. (2012). Conflict, provocation and fights among boys in a South African high school. Gender and Education, 24(5), 483-498.

Harré, R., \& van Langenhove, L. (1999). The dynamics of social episodes. In R. Harre \& L. van Langenhove (Eds.), Positioning theory (pp. 1-31). Oxford: Blackwell.

Jewkes, R., \& Morrell, R. (2010). Gender and sexuality: Emerging perspectives from the heterosexual epidemic in South Africa and implications for HIV risk and prevention. Journal of International AIDS Society, 13(6), 1-11.

Langa, M. (2010). Contested multiple voices of young masculinities amongst adolescent boys in Alexandra Township, South Africa. Journal of Child \& Adolescent Mental Health, 22(1), 1-13.

Lindegger, G., \& Quale, M. (2009). Masculinity and HIV/AIDS. In P. Rohleder, L. Swartz, S. C. Kalichman \& L. C. Simbayi (Eds.), HIV/AIDS in South Africa 25 years on: Psychosocial perspectives (pp. 41-54). New York: Springer.

McCormack, M., \& Anderson, E. (2010). The re-production of homosexually-themed discourse in educationally-based organised sport. Culture, Health \& Sexuality, 12(8), 913-927.

Morrell, R., Jewkes, R., \& Lindegger, G. (2012). Hegemonic masculinity/masculinities in South Africa: Culure, power and gender politics. Men and Masculinities, 15(1), 1130.

Parkes, J., \& Conolly, A. (2013). Dangerous encounters? Boys' peer dynamics and neighbourhood risk. Discourse: Studies in the cultural politics of education, 34(1), 94-106.

Peacock, D., Stemple, L., Sawires, S., \& Coates, T. J. (2009). Men, HIV/AIDS and human rights. Journal of Acquired Immune Deficiency Syndrome, 51(3), 119-125.

Phoenix, A., Frosh, S., \& Pattman, R. (2003). Producing contradictory masculine subject positions: Narratives of threat, homophobia and bullying in 11-14 year old boys. Journal of Social Issues, 59(1), 179-195.

Pollack, W. (1998). Real boys: Rescuing our sons from the myths of boyhood. New York: Owl Books.

Potter, J., \& Wetherell, M. (1987). Discourse and social psychology. London: Sage.

Ratele, K. (2008). Masculinity and male mortality in South Africa. African Safety Promotion, 6(2), 19-41.

Reardon, C. A., \& Govender, K. (2011). "Shaping up": The relationship between traditional masculinity, conflict resolution and body image among adolescent boys in South Africa. Vulnerable Children and Youth Studies, 6(1), 78-87.

Shand, T., Thomson-de Boor, H., van den Berg, W., Peacock, D., \& Pascoe, L. (2014). The HIV blind spot: Men and HIV testing, treatment and care in Sub-Saharan Africa. Institute of Development Studies Bulletin, 45(1), 53-60.

Shefer, T., \& Foster, D. (2009). Heterosex among young South Africans: Research reflections. In M. Steyn \& M. van Zyl (Eds.), The price/the prize: Shaping sexualities in the new South Africa (pp. 267-289). Cape Town: HSRC Press.

Shefer, T., Kruger, L., \& Schepers, Y. (2015). Masculinity, sexuality and vulnerability in 'working' with young men in South African contexts: 'You feel like a fool and an idiot ... a loser'. Culture, Health \& Sexuality, 17(sup2), 96-111. 
Sommer, M., Likindikoki, S., \& Kaaya, S. (2015). Bend a fish when the fish is not yet dry": Adolescent boys' perceptions of sexual risk in Tanzania. Archives of Sexual Behavior, 44(3), 583-595.

Tillotson, J., \& Maharaj, P. (2001). Barriers to HIV/AIDS protective behaviour among African adolescent males in township secondary schools in Durban, South Africa. Society in Transition, 32(1), 83-100.

Tucker, L. A., \& Govender, K. (2016). "Sticks and stones": Masculinities and conflict spaces. Gender and Education, 29(3), 352-368. Wetherell, M., \& Edley, N. (1999). Negotiating hegemonic masculinity: Imaginary positions and psycho-discursive practices. Feminism \& Psychology, 9(3), 335-356.

Wetherell, M., \& Edley, N. (2014). A discursive psychological framework for analyzing men and masculinities. Psychology of Men \& Masculinity, 15(4), 355-364.

Wood, K., \& Jewkes, R. (2001). 'Dangerous' love: Reflections on violence among Xhosa township youth. In R. Morrell (Ed.), Changing men in Southern Africa (pp. 317336). Pietermaritzburg: University of Natal Press.

Yamakawa, Y., Forman, E., \& Ansell, E. (2005). The role of positioning in constructing an identity in a third grade mathematics classroom. In K. Kumpulainen, C. E. HmeloSilver \& M. César (Eds.), Investigating classroom interaction: Methodologies in action (pp. 179-202). Rotterdam: Sense Publishers. 